\title{
Numerical Simulation of Welding Process for Q235 Steel Plate
}

\author{
Yukun Yang \\ Tianjin Maritime College, Tianjin, China
}

\begin{abstract}
In this paper, the weld of Q235 steel pipe with diameter of $60 \mathrm{~mm}$ and thickness of $4 \mathrm{~mm}$ is simulated and analyzed by MSC. Marc software. After modeling, applying material physical properties, setting weld bead and welding path, and applying boundary conditions, the operation results are analyzed and processed by submitting the work. According to the simulation results, different joints are selected to study the thermal cycle process and temperature distribution of joints under different joints.
\end{abstract}

\section{Establishment of finite element model}

In this simulation process, a numerical simulation is carried out for a long straight cylinder with a size of $\Phi 60$ * $4 \mathrm{~mm}$ and a model is established. Because the weld form is a butt weld, when the model is established, only half of the cylinder is built for simplified modeling [1]. The simplified model will speed up the entire calculation process and have no effect on the numerical simulation results.

In modeling, the length of the cylinder is set to be 50 $\mathrm{mm}$, the weld residual height is set to be $2 \mathrm{~mm}$, and the number of weld layers is set to be 3 layers. After the basic two-dimensional frame model is built, the grid is divided. In the welding process, the temperature variation gradient is very large [2], and the grid is divided in an uneven way. The closer the grid to the weld, the denser the grid, and the farther away from the weld, the more loose the grid. The two-dimensional grid model established is shown in Figure 1:

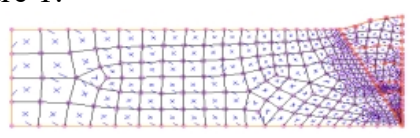

Figure 1. Two-dimensional grid model

Then, 6 set units are set up. subsequently, the twodimensional grid model is extended and rotated into a three-dimensional model, during which, some redundant points are generated, which can be swept with the "SWEEP " tool. The three-dimensional model diagram established is shown in Figure 2:

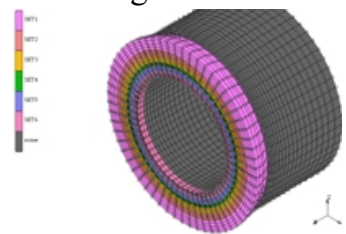

Figure 2. Generation of three-dimensional model

\footnotetext{
a Corresponding author: author@e-mail.org
}

\section{Application of material performance}

The mechanical property and chemical composition of the mother material are matched with the welding materials selected [3], so it is approximately considered that the material property of the weld bead is consistent with that of the mother material. After the parameters are applied, the parameter settings are assigned to all cells. The specific physical parameters are shown in Table 1.

Table 1. Physical performance parameters of Q235 steel pipe

\begin{tabular}{|c|c|c|c|c|c|}
\hline $\begin{array}{c}\text { Young's } \\
\text { modulus } \\
(\mathrm{GMPa})\end{array}$ & $\begin{array}{c}\text { Poisson } \\
\text { ratio }\end{array}$ & $\begin{array}{c}\text { Density } \\
(\mathrm{Kg} / \mathrm{m} 3)\end{array}$ & $\begin{array}{c}\text { Yield } \\
\text { strength } \\
(\mathrm{MPa})\end{array}$ & $\begin{array}{c}\text { Condu- } \\
\text { ctivity } \\
(\mathrm{S} / \mathrm{m})\end{array}$ & $\begin{array}{c}\text { Specific } \\
\text { heat } \\
\text { capacity } \\
\left(\mathrm{J} / \mathrm{kg} \cdot{ }^{\circ} \mathrm{C}\right)\end{array}$ \\
\hline 201 & 0.3 & 7800 & 235 & 40 & 500 \\
\hline
\end{tabular}

\section{Establishment of welding path}

The welding path indicates the trajectory and actual walking direction of the weld seam in the welding process [4]. The weld shape of this experiment is a ring weld, so the weld layer is set to a ring shape. The setting form of welding layer is shown in Figure 3:

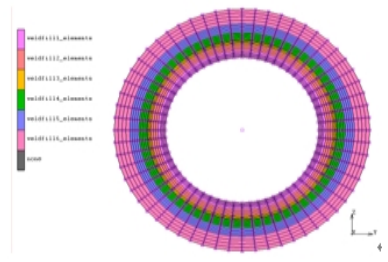

Figure 3. Welding layer setting

The welding path is the tangent direction of these nodes, that is, $Z$ direction. The direction of welding arc is downward, that is, $\mathrm{Y}$ direction. The specific path display is enlarged and processed as shown in Figure 4. 


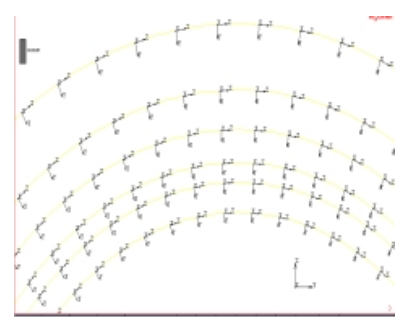

Figure 4. Welding path

\section{Setting of weld bead}

The "WELD FILLERS" command in the "MODELING TOOLS" function of the MSC.Marc software is used to set the weld bead [5]. The melting point temperature of each layer of weld metal is set to $1500^{\circ} \mathrm{C}$, and the parameters of each layer are added to the set unit. The setting pattern after the bead is shown in Figure 5:

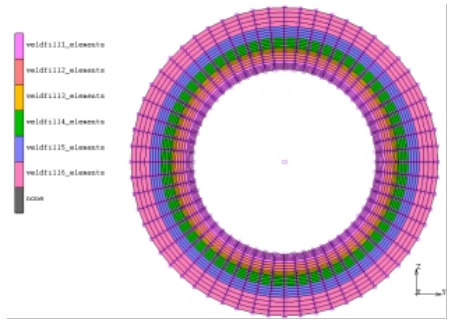

Figure 5. Setting pattern of the welding path

\section{Application of boundary conditions}

\subsection{Selection of welding heat source}

There are three types of welding heat sources for numerical simulation, and each heat source model has its own unique advantages and scope of use. The heat source model used in this paper is a dual ellipsoid model. The distribution function of the dual ellipsoid heat source consists of two 1/4 ellipsoids, as shown in Figure 6.

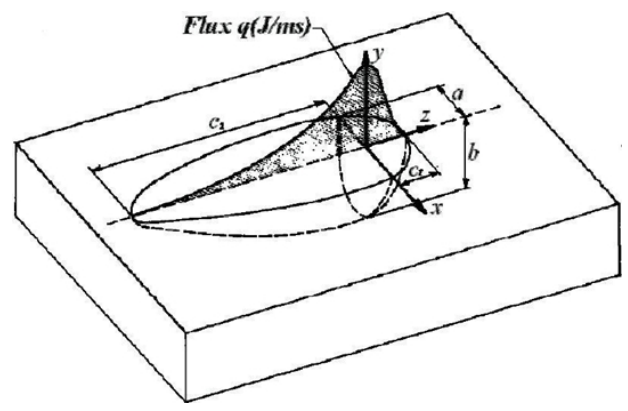

Figure 6. Double ellipsoid heat source model

\subsection{Setting of Thermal Boundary Conditions}

When the thermal boundary conditions are set, the convective heat transfer surface of the model is the contact surface between the workpiece and the air. The inner surface, the outer surface and the end surface of the workpiece are in contact with the air, and thermal boundary conditions are required to be set [3]. The symmetry surface does not participate in the heat exchange process. The model diagram after the thermal boundary condition is set is shown in Figure 7.

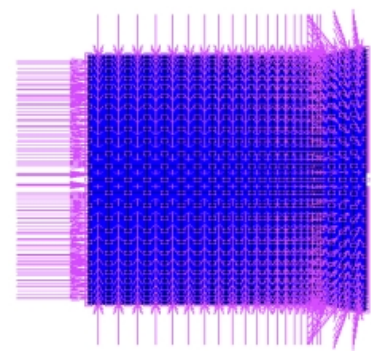

Figure 7. Thermal boundary conditions

\section{Setting and operation of working conditions}

The use of "LOADCASE" function of MSC.Marc software can achieve the setting process of the working condition [6]. The cooling time and time step settings are required for each layer, and the cooling time is consistent with the parameters of the time step. The working condition pattern of the weld setting is shown in Figure 8.

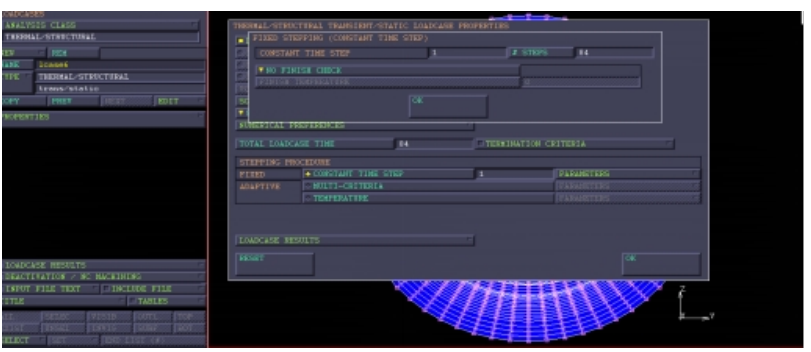

Figure 8. Setting pattern of weld conditions

\section{Analysis of simulation results}

The analysis process of the simulation results is very complicated, and the analysis time is proportional to the complexity of the model [7]. The calculation results can be viewed in the interface, and the temperature field of the welding process can be viewed every second[6]. The following is an example of a temperature field distribution selected for a weld.

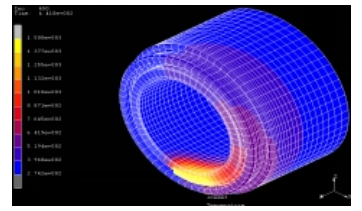

(a)

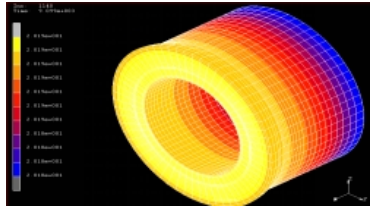

(b)
Figure 9. Distribution of temperature field (a) (b)

As shown in the Figure above, the excerpts are the temperature field distribution of steps 215 and 1140, respectively. Step 215 is the temperature field generated by the welding position of the second layer of weld. It can be seen that the temperature field at the position overlaps 
with the end of the first layer of weld; Step 1140 is the temperature field at which the weld is cooled to room temperature. It can be seen from the bar code on the left that the test piece has cooled to a temperature of around $20^{\circ} \mathrm{C}$, which is also consistent with the initial set value.

\section{Conclusions}

In this paper, the numerical simulation of the temperature field of the weld metal of Q235 steel plate is carried out. The nodes in different regional locations are selected, and the corresponding distribution rules are obtained, which are summarized as follows:

(1) The melting point value of the weld metal is the same as the set parameters.

(2) There is heat transmission during the welding process. The temperature at the center of the weld is the highest. The closer to the parent metal on both sides, the lower the temperature, which is consistent with the theoretical facts. During the welding process, the temperature at the center of the weld can reach the melting point of the metal, away from the heat source, and the temperature gradually decreases, which is in accordance with the test setting.

\section{References}

1. Dong Zhibo, Wei Yanhong, Liu Renpei, Dong Zuyu. Three-dimensional Numerical Simulation of Welding Temperature Field of Stainless Steel [J]. Journal of Welding, 2004 (02).

2. Xue Zhongming, Yang Guangchen, Zhang Yanhua. Research Progress on Welding Temperature Field and Mechanical Field Simulation [J]. China Mechanical Engineering, 2002 (11).

3. Wu Chuansong. Welding Heat Process and Molten Pool Form [M]. Beijing: Mechanical Industry Press, 2007.

4. Li Meiyan, Gong Yong, Song Lixin et al. Numerical Simulation of Residual Stress in in-service Welded Joints of Pipeline Steel [J]. Welded Pipe, 2011, 34 (7): $18-22$.

5. Study on Continuous Cooling Transformation Behavior of Supercooled Austenite in X80 Pipeline Steel [D]. Tan Huijie. Inner Mongolia University of Science and Technology, 2015.

6. Li Weiwei, Liu Yaxu, Gao Huilin, Zhao Xinwei, Feng Yaorong, Ji Lingkang. Toughness Analysis of X80 Pipeline Steel Welding Heat Affected Zone [J]. Journal of Welding, 2006 (02).

7. Zhou Jianxin, Li Dongcai, Xu Hongwei. Research and Development of Numerical Simulation of Welding Residual Stress [J]. Metal forming process, 2003, 21 (6): 62-64. 